\title{
The Role of Core Value, Character and Entrepreneur Leadership towards Successful Entrepreneur
}

\author{
Yolandafitri Zulvia ${ }^{1}$, Arif Adrian ${ }^{2}$ \\ ${ }^{1}$ Dept. of Management, Faculty of Economics, Universitas Negeri Padang, Padang, Indonesia \\ $\triangle$ (e-mail) yolandafitri86@gmail.com \\ 2Dept. of Management, Faculty of Economics, Universitas Negeri Padang, Padang, Indonesia \\ $\triangle$ (e-mail) arifadrianse@gmail.com
}

\begin{abstract}
Leadership is one of the important factors in the successful of entrepreneurs in digital era at this time. There are many successful business leaders. On the other hand, a lot of entrepreneurs go down because they do not prepare themselves from the early age to understand their core values and characters. The ignorance negatively impacts their capacity to become success entrepreneurs. The success of business leaders cannot be separated from their characters and the core values. The social cognitive approach explains how a business leader can be successful. This approach can help to explain the relationship between an entrepreneur, his personality characteristics, his values and other dimensions that will help to predict whether the entrepreneur will be success or not. This paper aims to find the relationship between characters and values and successful entrepreneurs. It contributes to the business world, particularly entrepreneur to prepare a leader from the early ages to be a successful entrepreneur. Based on this literature, an entrepreneur can evaluate the character and core values. Further research is needed to examine the connection empirically.
\end{abstract}

Keywords: leadership, character, core values, and successful entrepreneurs

\section{Introduction}

Nowadays, In the digital era the existence of successful entrepreneurs in Indonesia is relatively low. The number of entrepreneur s in Indonesia is only 400.000 people. It means it is still far from the expected amount that ideally has two million entrepreneurs. Many imported goods entered to Indonesia and the limitation of capital support becomes a factor inhibiting the emergence of successful entrepreneurs in Indonesia. Besides that, the education and other competency approach to prepare the successful entrepreneurs to be a problem that should be solved (regarding from ministry manpower and transmigration, cited from wartaekonomi.co.id).

Various theories and research regarding the entrepreneurship indicate the presence of multiple streams of different views as the economic expert found that the presence of entrepreneurship in a society is determined by the consumer demand, the further finding found that the entrepreneurship can be learnt through training and experience. The sociologists found that the emerging of entrepreneurship in a society determined by value or culture embraced by the society, and psychologists found that the emerging of entrepreneurs are determined by the individual characteristic of each person.

The individual characteristic of each person related to the core value and character of an entrepreneur. It is supported by Kapp (2003) which stated that there are many perspectives which try to explain about the process of entrepreneurship as follows. First, the more traditional group of researchers have focused on the personality characteristics of the individual, such as risk taking and innovativeness and work values. Second, the second group of researchers have taken a social cognitive approach, looking at the relationship between individual and his or her environment. The relationship between entrepreneur, personality characteristics, values and other dimensions will help why some of them become entrepreneur and others not. 
Various reports show that there are still lack of successful entrepreneurs in Indonesia. Therefore, it is relevant to have a blueprint on how to prepare the next generation to provide the understanding and education about the importance of recognizing characters and core values for an entrepreneur. By so doing, they are able to prepare themselves to be successful business leaders. This literature review aims to analyze theoretical and research literature related to how to prepare young generations to be successful entrepreneurs and the interaction between core values, characters and entrepreneur leadership.

\section{Methods}

The research design is descriptive method. It aims to describe and interpret the objects in accordance with what it is. The study used the descriptive method, allowing to test the relationship between variables or associations and finding comparative relationships between variables. Using a descriptive correlational study to find a relationship based on the correlation coefficient between the core values, characters, and entrepreneur leadership.

\section{Results and Discussion}

\section{The Concepts of Core Value}

Values have been a central concept in the social sciences since their inception. For both Durkheim $(1893,1897)$ and Weber (1905), values were crucial for explaining social and personal organization and change. Values have played an important role not only in sociology, but in psychology, anthropology, and related disciplines as well. Values are used to characterize societies and individuals, to trace change over time, and to explain the motivational bases of attitudes and behavior.

Contemporary scholars such as Singer (1975), Rue (2001), and Fernandez and Hogan (2002) systematically examined the relationship between values and leadership. Singer reported that leaders with high human values attained higher success rates than leaders with high material values. Singer also reported that the value systems of successful leaders remained constant throughout the leaders' professional lives. Rue (2001) noted the personal values of leaders, whether explicit or implicit, determine the leaders' perceived qualities and shape the culture of their organizations.

Fernandez and Hogan (2002) studied values-based leadership and determined the leader's core values affect the formulation and execution of their strategies. Fernandez and Hogan also recommended that "organizations take into account a candidate's core values when filling leadership positions". Hyde and Weathington (2006) researched the congruence between personal values and work attitudes and reported a statistically significant positive correlation between the constructs of personal values and honesty that resulted in a positive and comfortable work environment. Fritzsche and $\mathrm{Oz}$ (2007) researched the association between personal values and decision making and determined that altruistic values contributed positively to ethical decision making.

The conclusion from all definition above, core value has an important role in establishing a successful leader, core value closely associated to attitudes and behavior. These two things will support the success of an entrepreneur in running their business, in addition the core value also gives a major contribution for an entrepreneur to determine the strategy and ability in decision making.

Values are principles or standards we believe are important or worthwhile. They form the underlying priorities that guide our decisions and behavior. Values we consistently rank higher than others are what we call "core values" (Klatt, 2009).

Ten types of values that exist then divided again by Schwartz (1992) into four categories as follows. First, self-transcendence, that is the values that prioritize the interest of others (altruistic), such as universalism and benevolence. Second, self-enhancement, which is the opposite of previous category, that is the value which are more concerned with self-interest (egoistic), such as power and achievement, third, openness, consists of three types, for instance a self-direction, stimulation and hedonism. Finally, conservation, consists of three types, namely tradition, conformity and security.

There are ten types of values:

1. Power; a desire to control a group of people and available resources. 
2. Achievement; want to show the success demonstrate in achieving something or authority.

3. Stimulation; a courage in accepting the challenges in life.

4. Self-direction; the ability to choose their own actions and thoughts.

5. Hedonism; satisfaction upon themselves.

6. Universalism; a desire to motivate to improve and protect others.

7. Benevolence; a desire to motivate people who have a close relationship.

8. Tradition; a desire to preserve the culture. customs and religion affiliation.

9. Conformity; a restriction of the possible violation of the social norms and regulations.

10. Security; a desire to maintain the stability for ourselves and environment.

According to Rue (2001), it is essential for individuals to defines the personal values that are at the core of their being. Knowing these core values help individuals understand how and in what ways these values influence their leadership actions. It is essential to recognize that as a leader, a person may be asked to make many difficult and perhaps "either/or" decision, as well as work with individuals whose values are very different from their own. As an additional element to successful values based leadership, Rue (2001) encourages individuals to consciously identify their specific values and their leadership qualities. He believes values are "who you are," and qualities others see in a person, and how effective these qualities will be in meeting the leadership challenges in which the person engages. A leader is at their most effective when they not only have identified their values, but have discovered ways to honor them through action.

\section{The Concepts of Character}

Popularly, character has been considered that aspect of the person that forms the foundation for behavior. One of the best-known treatments of character on this level is that of Sheehy (1990). According to Sheehy, character is a pattern of behavior that is engraved through significant experiences and decisions. It is evident by observing a person's "important threads of experience" that person's life story. Others have continued a similar framework and have propagated the perspective that character is a multifaceted dimension of personality that incorporates all things such as values, morals, attitudes, interpersonal traits, intrapsychic processes, and personal interests and preferences (Hogan \& Sinclair,1997). However, this perspective serves to continue the confusion about how each of these constructs differ as well as relate to each other.

Character is "consistency in behavior across time" and includes "more than just a sense of self" (Leonard, 1997). In addition, personal beliefs are included in the character components of personality. Character, then, is the realm of impulse control and includes volitional elements. As such, character is the component of personality that corresponds with belief in the Fishbein and Ajzen (1975) model since one's general beliefs are conceptualizations of the way things work from a social learning perspective and lead to attitudes upon which an individual eventually acts (Ponton \& Carr, 1999).

According to Klann (2003), the role of character in effective leadership has also been recognized in the business world, almost people know intuitively that good character helps people reach their full potential and achieve success, increases productivity, enhances self-acceptance, self-confidence, energy, and enthusiasm, and improve interpersonal relationship.

Character is based on the core values of the leader. Character influences his/her vision, goals, selfconcept, strategies, work ethic, attitude, perception, code of ethics, behavior, and the search for excellence (Sankar, 1997). "Be careful of your thoughts, for your thoughts become your words; Be careful of your words, for your words become your deeds; Be careful of your deeds, for your deeds become your habits; Be careful of your habits, for your habits become your character; Be careful of your character, for your character becomes your destiny" (Kouzes and Posner, 2003).

According to Maxwell (2007) in his book "The 21 Indispensable Qualities of a Leader", a world leadership expert, "Charismsa can take you up to the top, but only a good character who defend it". That means without a good character, a leader who had reached the top will not last long. Because once it caught there is a flaw in the character, so that it will lose its reputation soon. 
Typical characteristics of entrepreneurs (Schermerhorn, 2004) internal locus of control, high energy level, high need for achievement, tolerance for ambiguity, self-confidence, action oriented.

There are many characteristics of entrepreneurs, and some of those are:

1. Internal locus of control: entrepreneurs believe that they are in control of their own destiny, they are self-directing and like autonomy;

2. High energy level: entrepreneurs are persistent, hard working, and willing to exert extraordinary efforts to succeed;

3. High need for achievement: entrepreneurs are motivated to accomplish challenging goals, they thrive on performance feedback;

4. Tolerance for ambiguity: entrepreneurs are risk takers, they tolerate situations with his degrees of uncertainty;

5. Self-confidence: entrepreneurs feel competent, believe in themselves, and are willing to make decisions;

6. Passion and action oriented: entrepreneurs try to act ahead of problems, they are self-reliant, they want to get things done and not waste valuable time;

7. Self-reliance and desire for independence: entrepreneurs want independence, they are selfreliance, they want to be their own boss, not work for others;

8. Flexibility: entrepreneurs are willing to admit problems and errors, and to change a course of action when plans are not working.

Character is defined as a disposition or trait, a way of thinking, being guided by a set of rules or principles, and a behavior or action (Bass, 2008). The key leader characteristics help the leader acquire necessary skills, formulate and organizational vision and an effective plan for pursuing it, and take the steps needed to implement the vision into reality (Kirkpatrick and Locke, 1991). From the above definition it can be seen that the character has an important role in the success of business leaders, with the character that they own the entrepreneur are able to implement their company vision and able to determine their attitude and act appropriate with the goal and survive from the various pressures.

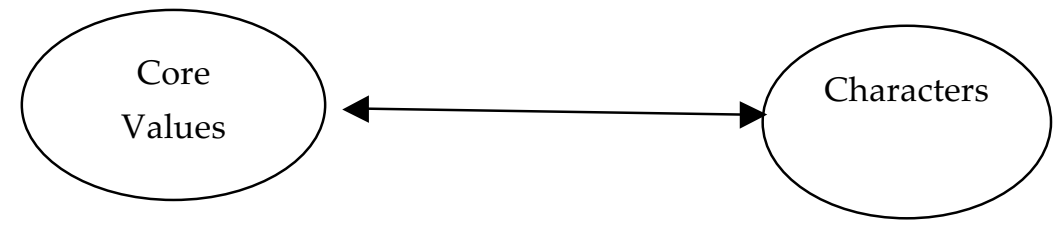

Figure 1 The relationship between core values and characters

Picture 1 shows the relationship between the core value and character, the theory on core value of Schwart research (1992) with the character theory of Schermerhorn (2004). The details of the relationship between the two research on core value and character are presented in Table 1.

Table 1 The relationship between core values and characters

\begin{tabular}{|c|c|c|c|}
\hline No & Core Values (Schwart, 1992 ) & $\begin{array}{l}\text { Have a relationship } \\
\text { with }\end{array}$ & Characters (Schermerhorn, 2004) \\
\hline 1 & $\begin{array}{l}\text { Power; a desire to control a } \\
\text { group of people and available } \\
\text { resources }\end{array}$ & & $\begin{array}{l}\text { Self reliance and desire for } \\
\text { independence: entrepreneurs } \\
\text { want independence, they are self- } \\
\text { reliant, they want to be their own } \\
\text { boss, not work for others }\end{array}$ \\
\hline 2 & $\begin{array}{l}\text { Achievement; want to show } \\
\text { the success demonstrate in } \\
\text { achieving something or } \\
\text { authority }\end{array}$ & & $\begin{array}{l}\text { High energy level: entrepreneurs } \\
\text { are persistent, hard working, and } \\
\text { willing to exert extraordinary } \\
\text { efforts to succeed }\end{array}$ \\
\hline 3 & $\begin{array}{l}\text { Stimulation; A courage in } \\
\text { accepting the challenges in }\end{array}$ & & $\begin{array}{l}\text { Self-confidence: entrepreneurs } \\
\text { feel competent, believe in }\end{array}$ \\
\hline
\end{tabular}




\section{life}

4 Self-direction; The ability to choose their own actions and thoughts

5 Hedonism; satisfaction upon themselves

6 Universalism; A desire to motivate to improve and protect others

7 Benevolence; A desire to motivate people who have a close relationship

8 Tradition; A desire to preserve the culture. customs and religion affiliation

9 Conformity; A restriction of the possible violation of the social norms and regulations

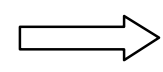

10 Security; A desire to maintain the stability for ourselves and environment themselves, and are willing to

make decisions

Passion and action-oriented: entrepreneurs try to act ahead of problems, they are self-reliant, they want to get things done and not waste valuable time

Self-reliance and desire for independence: entrepreneurs want independence, they are selfreliant, they want to be their own boss, not work for others High energy level: entrepreneurs are persistent, hard working, and willing to exert extraordinary efforts to succeed

Self-confidence: entrepreneurs feel competent, believe in themselves, and are willing to make decisions

Internal locus of control: entrepreneurs believe that they are in control of their own destiny, they are self-directing and like autonomy Flexibility: entrepreneurs are willing to admit problems and errors, and to change a course of action when plans are not working

Tolerance for ambiguity: entrepreneurs are risk takers, they tolerate situations with his degrees of uncertain

Table 1 show that the core values have a relationship with the characters, some previous theories stated that core values and character have an interrelationship. Sankar (1997) stated that the character is based on the core value of the leader. Character influences his/her vision, goals, self-concept, strategies, work ethic, attitude, perception, code of ethics, behavior, and the search for excellence. So, it can be concluded that the core value and character support an entrepreneur to be successful.

\section{Entrepreneur Leadership}

An entrepreneur can be regarded as a person who has the initiative skill and motivation to set up a business or enterprise of his own and who always looks for high achievements. He is the catalyst for social change and works for the common good. They looks for opportunities, identifies them and seizes them mainly for economic gains. An action oriented entrepreneur is a highly calculative individual who is always willing to undertake risks in order to achieve their goals (Turan et al., 2001).

An entrepreneur is someone who perceives a new idea and creates an organization to harvest the opportunity (Price, 2000). An entrepreneur is one who creates a new business in the face of risk and uncertainty for the purpose of achieving profit and growth by identifying significant opportunities and assembling the necessary resources to capitalize on them (Zimmerer \& Scarborough, 2008). 
Entrepreneur is an individual who takes initiative to bundle resources in innovative ways and is willing to bear the risk and/or uncertainty to act (Hirsch, Peters, and Shepherd; 2010). Entrepreneurs as the person who destroys the existing economic order by introducing new products and services, by creating new forms of organization, or by exploiting new raw materials (Schumpeter in Alma, 2008).

According to Mixon (2008) definitions an entrepreneur is an innovator who establishes a new business offering new or existing products or services for the reward of profit. Entrepreneurs have strong beliefs about market opportunities and willingly accept a high level of personal, professional and financial risk. An entrepreneur possesses a variety of different characteristics that provide a skill set for achieving success and a high level of reward.

Mixon (2008) also defines others characteristic entrepreneur, the entrepreneur has an enthusiastic vision, the driving force of an enterprise. The entrepreneur's vision is usually supported by an interlocked collection of specific ideas not available to the marketplace. The overall blueprint to realize the vision is clear, however details may be incomplete, flexible, and evolving. The entrepreneur promotes the vision with enthusiastic passion. With persistence and determination, the entrepreneur develops strategies to change the vision into reality. The entrepreneur takes the initial responsibility to cause a vision to become a success. Entrepreneurs take prudent risks. They assess costs, market/customer needs and persuade others to join and help. An entrepreneur is usually a positive thinker and a decision maker. An entrepreneur needs inspiration, motivation and sensibility.

As a further perspective, Darling and Beebe (2007) noted that entrepreneurs are focused around three broad areas: innovation, risk taking, and developing a proactive stance in the market. Defining an entrepreneur depends on which aspect of research and theory one evaluates.

According to Bangun (2012) in the book of Academic Business and government leadership there are 14 keys to successful business leadership, namely:
1. Risk taker
8. Creative and innovative
2. Hard worker
9. Balanced life
3. Integrity
10. People focus
4. Humble
11. Seeks opportunity
5. Optimistic
12. Adaptive
6. Have goals
13. Lead by example
7. Costumer focus
14. Work is a part of spiritual process

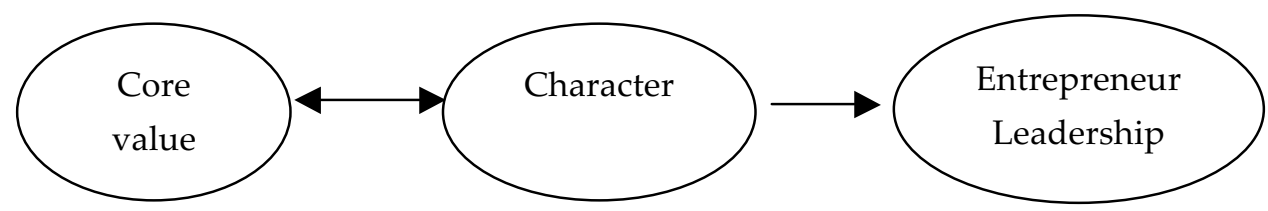

Figure 2 relationship between core value, character and entrepreneur leadership

The previous explanation indicates that there is a relationship between core values and character. Picture 2 further presents that a leadership entrepreneur is formed by core value and character that have a mutual influencing each other.

\section{Conclusions}

Core values and character are the foundation of every individual to be able to become successful business leaders, character is based on the core values of the leader. Character Influences his / her vision, goals, self-concepts, strategies, work ethics, attitude, perception, code of ethics, behavior, and the search for excellence (Cage, 1997).From the definition, we know that to be a successful business leader, an entrepreneur must be able to recognize and understand the character and the value they have. By recognizing the character and value that they have, in the end they are able to act in 
accordance with their character and value, so that in running the business they are able to determine the strategy, make decisions and how to act based on their values and character.

The explanation of the Schwart (1992) on ten types of values that exist then divided again by Schwartz into four categories, namely: (1) self-transcendence, that is the values that prioritize the interest of others (altruistic), such as universalism and benevolence (2) self-enhancement, which is the opposite of previous category, that is the value which are more concerned with self-interest (egoistic), such as power and achievement (3) openness, consists of three types, for instance a self-direction, stimulation and hedonism (4) conservation, consists of three types, namely tradition, conformity and security. Each values are actually has a relationship of mutual affecting with the character, where through Schermerhornn (2004) that describes the criteria for the character of an entrepreneur is like an internal locus of control, high energy level, high need for achievement, tolerance for ambiguity, selfconfidence, action oriented, self-reliance and desire for independence, and flexibility.

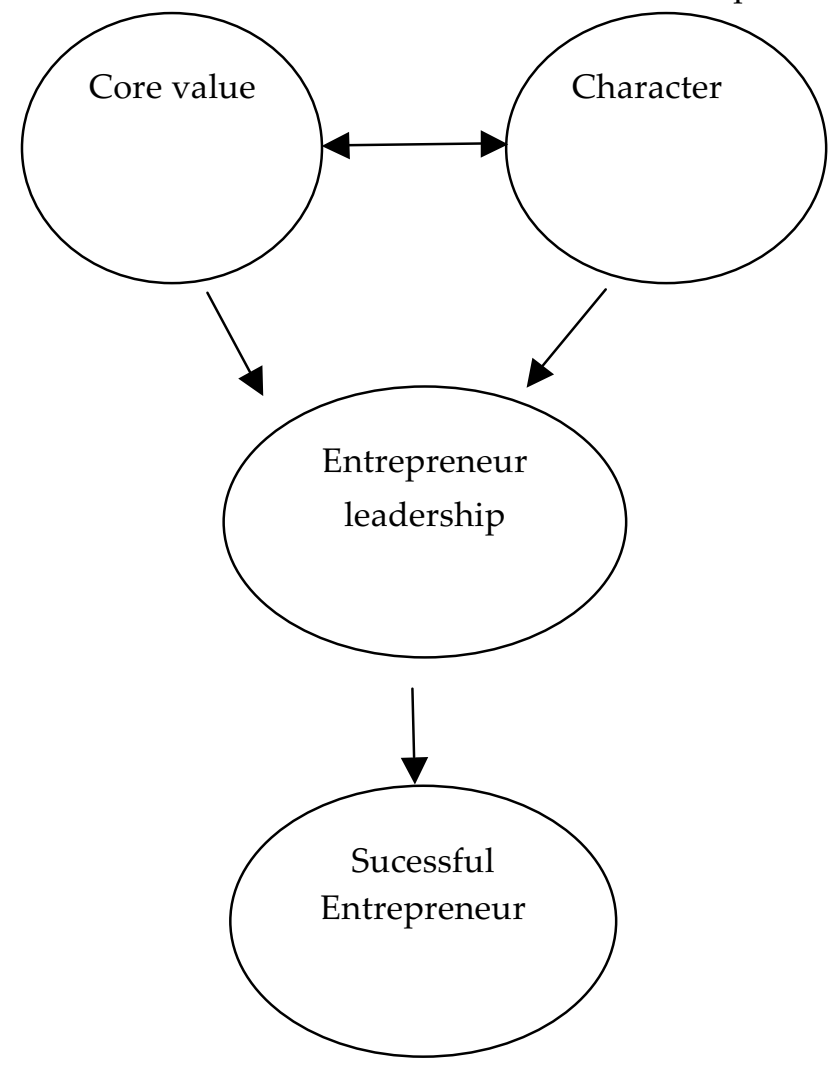

Figure 3 The relationship between core value, character, entrepreneur leadership, and success

Picture 3 shows that to be a successful business leader, an entrepreneur must consider the character and Core values they have. Where the character and core values form the basis for an entrepreneur to be able to run the business day-to-day and how to act in daily life as well as pay attention the surrounding environment and the changes that occur. Then by recognizing the character and core values a business leader expected to be able to implement its business strategy well and can make decisions wisely and quickly. Core values and character are mutually supportive to the requirements to become a a successful business leader. Where the quality of a business leader can be seen from the core value, character and entrepreneurial leadership they have. It is appropriate with the theory Schwartz (1992) on the theory of core values and Schermerhorn (2004) about the character and the theory of entrepreneurial leadership Bangun (2010).

The relationship between the three theories can explain that to become a successful business leader so an entrepreneur must be able to understand the core values, character and leadership entrepreneur they have to be able become a successful business leader. 


\section{References}

Bass, B. M. (2002). Cognitive, social, and emotional intelligence of. In R. E. Riggio, S. E. Murphy, \& F. J. Pirozzolo (eds) (hal. Multiple intelligences and leadership (pp. 105-118)). Mahwah, NJ:: Lawrence Erlbaum Associates.

Bangun, Y, R. \& Anggoro Y. (2010). Kepemimpinan ABG (Academic, Business and Goverment). SBMITB.

Durkheim, E. (1893/1964). The division of labor in society. Glencoe, IL.: Free Press .

Fernandez, J. E \& Hogan, R. T. (2002). Values-based leadership. Journal for Quality \& Participation, 25(4), 25-27 Retrieved September 30, 2007, from Academic Research Premier database.

Fishbein, M., \& Ajzen, I. (1975). Belief, attitude, intention, and behavior: An introduction to theory and research. Reading, MA: Addison-Wesley .

Fritzsche, D. J., \& Oz, E. (2007). Personal values' influence on the ethical dimension of decision making. Journal of Business Ethics , 75, 334-343. Retrieved October 1, 2007, from Business Source Complete database.

Hogan, R., \& Sinclair, R. (1997). For love or money? Character dynamics in consultation. Consulting Psychology Journal: Practice \& Research , 49(4), 256-267.

Hyde, R. E., \& Weathington, B. L. (2006). The congruence of personal life values and work attitudes. Genetic, Social \& General Psychology Monographs , 132, 151-190 Retrieved October 1, 2007, from Academic Search Premier database.

Kapp, J. (2003, april 1, 2003). "A Psychological Model of Entrepreneurial Behaviour". Journal of Academy of Business and Economics .

Kirkpatrick, S. A., \& Locke, E. A. (1991). Leadership: Do traits matter? Academy of Management Executive , 5(2), 48-60.

Klann, G. (2007). Building character: Strengthening the heart of good leadership. San Francisco: Jossey-Bass.

Klatt, J. (2009). Understanding Our Values \& Character. A Leadership Curriculum for College Students , 2-3 University of Wisconsin-Madison.

Kouzes, J. M., \& Posner, B. Z. (2003). Leadership practices inventory (3rd ed.). San Francisco: : JosseyBass.

Leonard, H. S. (1997). The many faces of character. Consulting Psychology Journal: Practice \& Research, 49(4), 235-245.

Maxwell, J. C. (2007). The 21 Indispensable Qualities of a Leader: Becoming the Person Others Will Want to Follow. New York: Thomas Nelson; 2 edition (September 18, 2007).

Ponton, M. K., \& Carr, P. B. (1999). A quasi-linear behavioral model and an application to selfdirected learning. Hampton, VA: Langley Research Center, National Aeronautics and Space Administration, Technical Memorandum No. TM-1999-209094.

Rue, B. (2001). Values-based leadership. Program Manager , 30(4), 12-16. Retrieved.

Sankar, Y. (2003). Character not charisma is the critical measure of leadership excellence. Journal of Leadership \& Organizational Studies, 9(4), 45-55, Retrieved November 24, 2007, from ABI/INFORM Global database.

Sankar, Y. (1997). value based leadership, social values. presented at a conference at cambridge university, United Kingdom .

Schermerhorn. (2004). Management, John Wiley \& Sons. New York: eight edition.

Schwartz, S. H. (1992). Universals in the content and structure of values: Theory and empirical. Advances in experimental social psychology (Vol. , (pp. 1-65). New York: Academic Press.

Sheehy, G. (1990). Character:. Dalam Character: America's search for leadership (Rev. ed.). New York: Bantam Books.

Singer, H. (1975). Human values and leadership. Business Horizons from Business Source Complete database, 18(4), 85-88 A Retrieved September 30, 2007.

Weber, M. (1905/1958). The Protestant ethic and the spirit of capitalism. New York: Scribner's . 